\title{
Medidas adoptadas por el Gobierno de El Salvador en el contexto de la pandemia del covid-19
}

\section{Measures taken by the Government of El Salvador in the context of the Pandemic for the covid-19}

\section{Medidas tomadas pelo governo de El Salvador no contexto da pandemia para o covid-19}

Oscar Stanley Pineda Viana*

Máster Internacional en Administración Financiera y Hacienda Pública de la Universidad Nacional de Educación a Distancia (UNED) de Madrid. Docente universitario en Finanzas y experiencia en finanzas públicas desde 1991 en El Salvador. Miembro Grupo de Investigación Conocimientos Tributarios Latam.ostanleypineda@gmail.com/https://orcid.org/0000-0001-9035-3966 Dor: https://doi.org/10.18601/16926722.n18.09 


\section{Resumen}

El artículo presenta información fehaciente, clara y precisa acerca de las principales medidas en materia impositiva que El Salvador y su Administración Tributaria adoptaron con ocasión de la pandemia por el covid-19, declarada por la Organización Mundial de la Salud a partir del mes de marzo de 2020; el impacto fiscal de la pandemia es descrito por el Ministerio de Hacienda de El Salvador en su página web:

"De acuerdo al FMI (Fondo Monetario Internacional) la caída en los ingresos será el principal responsable del aumento en el déficit fiscal de aproximadamente $8.75 \%$ respecto al PIB; [...] la calificadora de riesgo Fitch, en su más reciente actualización de calificación de riesgo indicó que la caída esperada de ingresos como efecto de la contracción económica podría representar un 15\% respecto al 2019” (Ministerio de Hacienda, s.f.).

Palabras clave: suspensiones; prórroga; plazo; pago electrónico; multas; intereses; recargos.

\section{Abstract}

We wish to provide the reader with reliable, clear and precise information on the main measures in tax matters that El Salvador and its Tax Administration (TA) adopted, on the occasion of the Pandemic by COVID-19 as of March 2020. The fiscal impact of the pandemic is described by the Ministry of Finance of El Salvador on its website:

"According to the IMF (International Monetary Fund) the fall in income will be the main responsible for the increase in the fiscal deficit of approximately $8.75 \%$ with respect to the GDP; $[\ldots]$ the risk rating agency Fitch, in its most recent risk rating update, indicated that the expected drop in income as a result of the economic contraction could represent 15\% compared to 2019" (Ministerior de Hacienda de El Salvador, s.f.).

Key words: Suspensions; extension; term; electronic payment; fines; interest; charges.

\section{Resumo}

Desejamos fornecer ao leitor informações confiáveis, claras e precisas sobre as principais medidas em matéria tributária que El Salvador e sua Administração Tributária (TA) adotaram, por ocasião da Pandemia pelo CovID-19, a partir de março 2020. O impacto fiscal da pandemia é descrito pelo Ministério das Finanças de El Salvador em seu site:

“Segundo o FMI (Fundo Monetário Internacional), a queda na renda será a principal responsável pelo aumento do déficit fiscal de aproximadamente $8,75 \%$ em relação ao PIB; 
[...] a agência de classificação de risco Fitch, em sua atualização mais recente de classificação de risco, indicou que a queda esperada na receita como resultado da contração econômica pode representar 15\% em comparação a 2019" (Ministerior de Hacienda de El Salvador, s.f.).

Palavras chave: Suspensões; prorrogação; prazo; pagamento eletrônico; multas; juros; sobretaxas.

\section{Introducción}

El Salvador está situado en Centroamérica, tiene una extensión territorial de 21.041 kilómetros cuadrados, un aproximado de 6,4 millones de habitantes, lo que lo hace uno de los más densamente poblados de la región; su crecimiento económico, medido en función de su producto interno bruto (PIB), fue del 2,3\% para el año 2019, según datos del Banco Mundial; sin embargo, con el impacto de la pandemia de covid-19, la economía salvadoreña podría contraerse a $-4,3 \%$ en 2020 y existe una expectativa de que crezca un $4,8 \%$ para 2021.

Como en muchas de las economías latinoamericanas, la crisis global tiene un alto impacto, lo que agrava las finanzas públicas, así como su actividad económica en general; sin embargo, el Gobierno central adoptó acciones oportunas para la contención del virus y generó distintas iniciativas de ley, que en principio fueron aprobadas por el Congreso, a fin de viabilizar una serie de medidas en materia tributaria, que favorecen a los contribuyentes que se han visto afectados por la parálisis económica.

Este documento analiza las principales medidas que en materia tributaria han sido adoptadas e implementadas por la Administración Tributaria (AT) de El Salvador, con ocasión de la pandemia del covid-19, a partir del mes de marzo de 2020.

\section{Suspensiones}

Por Decreto 593 del Órgano Legislativo, de fecha 20 de marzo de 2020, se declaró el Estado de emergencia nacional, estado de calamidad pública y desastre natural en todo el territorio salvadoreño, en el marco establecido en la Constitución de la República de El Salvador, debido a la pandemia del covid-19, para los efectos de los mecanismos previstos en la Ley de Protección Civil, Prevención y Mitigación de Desastres, la Ley de Adquisiciones y Contrataciones de la Administración Pública, y demás leyes, convenios o contratos de cooperación o préstamo aplicables, a fin de facilitar el abastecimiento adecuado de todos los insumos de la naturaleza que fueren necesarios directamente para hacer frente a la mencionada pandemia. Dentro del articulado contenido en los incisos primero y segundo del artículo 9 del referido cuerpo de ley, fueron contenidas las siguientes medidas suspensivas, con efecto en las obligaciones civiles y mercantiles, siguientes: 
- Por el plazo de 30 días, a partir de la vigencia del decreto, los términos y plazos legales concedidos a los particulares y a los entes de la Administración Pública en los procedimientos administrativos y judiciales en que participan, cualquiera que sea su materia y la instancia en la que se encontraban, respecto a las personas naturales y jurídicas afectadas por las medidas decretadas.

Los cumplimientos de obligaciones contractuales, penalidades civiles y mercantiles, a toda persona imposibilitada de cumplir sus obligaciones por estar afectadas directamente por las medidas aplicadas en cumplimiento del decreto.

En el citado artículo se excluyó lo relativo a la materia penal, procesal penal y electoral; por otra parte, se facultó al comité de normas del Banco Central de Reserva de El Salvador para dictar la normativa correspondiente al sistema financiero. El plazo fue extendido al 24 de mayo de 2020 mediante el Decreto Legislativo 644, emitido el 14 de mayo de 2020.

\section{Medidas para facilitar el cumplimiento de obligaciones tributarias, cobranza, y recaudación y devolución de impuestos de la AT de El Salvador}

En el marco de la emergencia por el covid-19 en El Salvador, se tomaron medidas de carácter tributario, por medio de leyes o decretos legislativos que abordaremos a continuación; sin embargo, es necesario tener presente que la AT salvadoreña desarrolla las funciones de recaudación tributaria por medio de oficinas colectoras propias y de entidades del sistema financiero las cuales, a pesar de la pandemia, continuaron funcionando, ya sea de manera virtual o presencial. De igual forma, la Dirección General Tributaria mantuvo su labor en procesos de cobro, así como en las devoluciones del impuesto sobre la renta (aplicable a personas físicas y jurídicas).

\section{A. Ley especial y transitoria sobre la modalidad de pago del impuesto sobre la renta aplicable a pequeños contribuyentes, turismo, energía eléctrica, servicios de televisión, internet y telefonía y sobre la contribución especial para la promoción del turismo}

Conforme al Decreto Legislativo 598 del 20 de marzo de 2020, se promulgó la “Ley especial y transitoria sobre la modalidad de pago del Impuesto sobre la renta aplicable a pequeños contribuyentes, turismo, energía eléctrica, servicios de televisión, internet y telefonía y sobre la contribución especial para la promoción del turismo", en la cual se dictaron las siguientes disposiciones:

- Exoneración a empresas turísticas de la contribución especial para la promoción del turismo por tres meses. 
- Prórroga para la declaración del impuesto sobre la renta (ISR) del ejercicio 2019, hasta mayo de 2020, cuando el impuesto por pagar sea igual o menor a US\$25.000.00.

- Otorgamiento de plazos para pagar impuesto o anticipos a cuenta, mediante solicitud a la Dirección General de Tesorería (DGT).

- Las empresas del sector eléctrico podrán pagar el ISR del ejercicio fiscal 2019, en 8 cuotas sin interés y multas.

- Las empresas del sector telecomunicaciones, tales como; cable, telefonía e Internet, podrán:

- Pagar el ISR del ejercicio físcal 2019, en 8 cuotas sin interés y multas.

- Efectuar el Pago a cuenta del ISR, de los meses de marzo, abril y mayo de 2020, en 6 cuotas, siempre que preste al menos 2 de los citados servicios.

- Las personas naturales o jurídicas pueden pagar el ISR con valor a pago liquidado del ejercicio 2019, en 8 cuotas, sin interés y multas, cuando el impuesto por pagar sea igual o menor a US $\$ 10.000,00$.

\section{B. Disposiciones transitorias por medio de las cuales se simplifica el procedimiento de las donaciones de bienes por parte de las empresas reguladas en la ley de zonas francas industriales y de comercialización}

Mediante Decreto Legislativo 603 del 20 de marzo de 2020, fueron emitidas las “Disposiciones transitorias por medio de las cuales se simplifica el procedimiento de las donaciones de bienes por parte de las empresas reguladas en la ley de zonas francas industriales y de comercialización”, dentro de las cuales se declaró exento del pago de derechos arancelarios a la importación, del Impuesto a la Transferencia de Bienes Muebles y a la Prestación de servicios (IVA) y cualquier otro tipo de gravámenes de naturaleza fiscal o municipal, a todos los bienes internados al amparo de la Ley de Zonas Francas Industriales y de Comercialización por las personas naturales o jurídicas beneficiarias de la misma; y se reciban para ser donados al Gobierno de la República, concejos municipales e instituciones públicas y privadas, sin fines de lucro, de carácter humanitario, educativas u otros servicios a la comunidad, en beneficio de las personas afectadas por la emergencia nacional del covid-19, o bien que dichas donaciones también sean entregadas a entidades de socorro o que presten asistencia pública, tales como la Cruz Roja, Cruz Verde, Comandos de Salvamento y cualquier otra entidad de naturaleza similar, siempre para ser distribuidos entre la población afectada.

\section{Arancel cero a la importación de alimentos y productos básicos de limpieza, entre otros}

Mediante Decreto Legislativo 604, también del 20 de marzo de 2020, según artículo 2, fue modificado el arancel centroamericano de importación, únicamente para El Salvador, reduciendo a cero los aranceles correspondientes a los códigos arancelarios presentados 
en la tabla 1, medida que busca facilitar la entrada al país de productos de uso básico, lo cual incide en la recaudación tributaria.

\section{TABLA 1.}

\begin{tabular}{|c|c|c|}
\hline Código & Descripción & DAI \\
\hline 0402.21 .21 .00 & En envases de contenido neto inferior a $5 \mathrm{~kg}$ & 0 \\
\hline 0713.33 .40 .00 & Frijol rojo & 0 para una cuota de $25.000 \mathrm{TM}$ \\
\hline 1006.30 .90 .00 & - Otros & 0 para una cuota de $7.500 \mathrm{TM}$ \\
\hline 1101.00 .00 .00 & - Harina de trigo o de morcajo (tranquillón) & 0 \\
\hline 1102.20 .00 .00 & - Harina de maíz & 0 \\
\hline 1102.90 .30 .00 & - - Harina de arroz & 0 \\
\hline 2005.10 .00 .00 & - Hortalizas homogeneizadas & 0 \\
\hline 2005.59.00.00 & - - Los demás & 0 \\
\hline 2007.10 .00 .00 & - Preparaciones homogeneizadas & 0 \\
\hline 2104.20 .00 .00 & - Preparaciones alimenticias compuestas homogeneizadas & 0 \\
\hline 2106.90 .79 .00 & - Las demás & 0 \\
\hline 2828.90 .10 .00 & - Hipoclorito de sodio & 0 \\
\hline 3004.20 .10 .00 & - Para uso humano & 0 \\
\hline 3004.32 .10 .00 & - - Para uso humano & 0 \\
\hline 3004.50 .10 .00 & - Para uso humano & 0 \\
\hline 3004.90 .11 .00 & - Para uso humano & 0 \\
\hline 3004.90 .91 .00 & - Para uso humano & 0 \\
\hline 3401.11 .11 .00 & - - - - Medicinal, excepto el desinfectante & 0 \\
\hline 3401.11 .19 .00 & Los demás & 0 \\
\hline 3401.11 .20 .00 & $\begin{array}{l}\text { Productos y preparaciones orgánicos tensoactivos, usados } \\
\text { como jabón }\end{array}$ & 0 \\
\hline 3401.11 .30 .00 & $\begin{array}{l}\text { Papel, guata, fieltro y tela sin tejer, impregnados, recubiertos o } \\
\text { revestidos de jabón o de detergentes }\end{array}$ & 0 \\
\hline 3401.19 .00 .00 & - - Los demás & 0 \\
\hline 3401.20 .10 .00 & - - Jabón líquido, medicinal (excepto el desinfectante) & 0 \\
\hline 3401.20 .90 .00 & - - Otros & 0 \\
\hline 3401.30 .00 .00 & $\begin{array}{l}\text { - Productos y preparaciones orgánicos tensoactivos para el } \\
\text { lavado de la piel, líquidos o en crema, acondicionados para la } \\
\text { venta al por menor, aunque contengan jabón }\end{array}$ & 0 \\
\hline 3402.20 .00 .00 & -Preparaciones acondicionadas para la venta al por menor & 0 \\
\hline 3402.90 .20 .00 & - - Preparaciones para lavar y preparaciones de limpieza & 0 \\
\hline 3808.94 .10 .00 & $\begin{array}{l}\text { - A base de aceite de pino y de agentes tensoactivos de amo- } \\
\text { nio cuaternario }\end{array}$ & 0 \\
\hline 3808.94 .90 .00 & - Otros & 0 \\
\hline 4015.19 .00 .00 & - - Los demás & 0 \\
\hline 9619.00 .10 .00 & - De plástico & 0 \\
\hline 9619.00 .29 .00 & - - Los demás & 0 \\
\hline 9619.00 .39 .00 & - - Los demás & 0 \\
\hline 9619.00 .40 .00 & - De materia textil, de punto & 0 \\
\hline 9619.00 .90 .00 & - Otros & 0 \\
\hline
\end{tabular}

Fuente: tomado del Decreto Legislativo 604 de 2020. 
Asimismo, el artículo 4 del referido Decreto Legislativo estableció un arancel cero para el caso de los medicamentos del código arancelario 3004.90.91.00 - - - Para uso humano, la eliminación del arancel no aplica al ibuprofeno.

\section{Facilitación de compras en línea}

Asimismo, mediante Decreto Legislativo 605, de fecha 20 de marzo de 2020, fue emitida la Ley de Facilitación de Compras en Línea, la cual tiene como ámbito de aplicación, según su artículo 1, el siguiente:

La importación definitiva al territorio aduanero salvadoreño de bienes o mercancías sin carácter comercial, realizadas por personas naturales en línea, procedente de los Estados Unidos de América, bajo las modalidades de entrega rápida o Courier, envíos postales, pequeños envíos familiares y gestores de encomiendas por vía aérea, que tengan un valor inferior a Doscientos Dólares de Los Estados Unidos de América, no están sujetas al pago de derechos arancelarios a la importación, y están exentos de los requisitos no arancelarios.

De acuerdo con el artículo 2 de la referida Ley, se exceptúan de este beneficio la importación definitiva de medicamentos bajo prescripción e insumos médicos para uso humano y veterinario; los precursores químicos estipulados en la Convención de las Naciones Unidas Contra el Tráfico ilícito de Estupefacientes y Sustancias Psicotrópicas; armas de fuego, municiones, explosivos y materiales relacionados. Asimismo, según el artículo 3, el Ministerio de Hacienda, a través de las Direcciones Generales de Impuestos Internos (DGI) y de Aduanas (DGA), está facultado para la cancelación de los beneficios del decreto.

Por otra parte, el artículo 4 señala que, para el caso de las compras efectuadas por medio de comercio electrónico, se podrán sustituir los requisitos de la factura con la impresión del comprobante de pago emitido por la plataforma de comercio electrónico y, como último recurso, las capturas de imagen donde se señale el cargo reflejado del medio de pago utilizado con la identificación de compra en la aplicación respectiva, que debe ser mencionada; el artículo 5 dicta que el valor en aduanas se determinará a través del precio según factura, comprobante o visualización de pago de la plataforma electrónica; el flete, que será un $10 \%$ del precio del producto, y el seguro, que será el $1,50 \%$ sobre el precio del producto.

Respecto al procedimiento aplicable, el artículo 6 de la referida ley señala que las mercancías que se introduzcan al territorio salvadoreño bajo esta modalidad deben ampararse en una declaración simplificada, acumulada o individual, de acuerdo con el formato y las condiciones de presentación que la DGA establece, por medio de disposiciones administrativas de carácter general. 


\section{E. Ley Transitoria para facilitar el Cumplimiento Voluntario de Obligaciones Tributarias en virtud de la Emergencia Nacional ocasionada por la Pandemia por covid-19}

Por Decreto Legislativo 643 de fecha 14 de mayo de 2020, fue emitida esta ley, con el objeto de facilitar el cumplimiento voluntario de las obligaciones tributarias, en el contexto de la emergencia nacional, a consecuencia de la pandemia del virus en referencia.

El artículo 1 concede hasta el 30 de junio de 2020 para los sujetos pasivos clasificados como otros, medianos o grandes contribuyentes por parte de la DGII, así como las personas naturales no inscritas como contribuyentes del IVA, que no habían cumplido con la obligación de presentar la declaración de impuesto sobre la renta correspondiente al ejercicio impositivo de 2019, cuyo plazo legal venció el 30 de abril de 2020, es decir, se concedió una prórroga para:

- Presentar la declaración correspondiente sin que se causen multas, intereses, ni recargos.

- Efectuar modificación a la declaración que hubiere sido presentada hasta el 30 de abril de 2020, respecto del citado ejercicio, a fin de que realicen la liquidación del impuesto original o complementario sin multas, intereses o recargos, dentro de la vigencia del decreto; de igual forma, si hubiesen presentado y pagado la declaración del referido impuesto fuera del plazo legal establecido en la Ley de Impuesto sobre la Renta.

- Solicitar autorización de pago a plazos del impuesto sobre la renta y los respectivos pagos sin que se causen multas, intereses o recargos, si habiendo presentado su declaración dentro del correspondiente plazo legal, no lo solicitaron.

- Solicitar ampliación para quienes ya habían solicitado pago a plazos, también sin causar intereses, recargos y multas.

En el artículo 2 de la referida ley, concede hasta el 30 de junio de 2020, a los sujetos pasivos clasificados como grandes contribuyentes por parte de la DGII, las siguientes concesiones:

- Presentar y pagar la referida Contribución Especial, sin causar intereses, recargo, ni multas que no hubiesen presentado, ni pagado la declaración de la Contribución Especial a los Grandes Contribuyentes para el Plan de la Seguridad Ciudadana, cuyo plazo venció el 30 de abril de 2020.

- Modificar la declaración que hubiere sido presentada hasta el 30 de abril de 2020, respecto del citado ejercicio, en la que se determinaba un monto menor por pagar de la citada contribución al que legalmente corresponde, a fin de que realice la liquidación de contribución original o complementaria por pagar, sin que se causen multas, intereses o recargos, dentro de la vigencia del Decreto. 
- Modificar su declaración sin que se causen multas, intereses, ni recargos, si presentaron y pagaron la declaración fuera del plazo legal establecido en la Ley de Contribución Especial.

El artículo 3 de dicha ley brinda la posibilidad de presentar informes tributarios o cumplir con las obligaciones formales contenidas en las leyes tributarias cuyo vencimiento era el 30 de abril de 2020, por un periodo de 2 meses contados a partir de la vigencia del Decreto, sin que se causen multas.

TAbla 2.

\begin{tabular}{|c|c|}
\hline $\begin{array}{c}\text { Periodo de la obligación (contado a partir de la fecha } \\
\text { de vencimiento del plazo ordinario respectivo de } \\
\text { cada obligación) }\end{array}$ & Vencimiento de la obligación \\
\hline Marzo & Mayo \\
\hline Abril & Junio \\
\hline Mayo & Julio \\
\hline Junio & Agosto \\
\hline Julio & Septiembre \\
\hline
\end{tabular}

Fuente: información AT, Ministerio de Hacienda de El Salvador (2020).

De acuerdo con el artículo 5 de esta misma ley, el pago de las obligaciones tributarias comprendidas en el presente Decreto puede hacerse en efectivo, cheques de caja, de gerencia o certificados, Notas de Crédito del Tesoro Público (NTCI), tarjetas de crédito o débito aceptadas por la DGT y la AT; además, pone a disposición de los sujetos pasivos los mandamientos de ingreso por medio del sistema electrónico de su página web, servicios en línea o cualquier otro medio electrónico que facilite y viabilice a los sujetos pasivos el pago del impuesto oportunamente.

El decreto señala además, en el artículo 6, que para los casos en que los contribuyentes clasificados como medianos o como otros contribuyentes por parte de la DGII, así como para las personas naturales no inscritas como contribuyentes del IVA, soliciten plazo para el pago de sus obligaciones tributarias al amparo de este decreto, la DGT otorga mediante la resolución respectiva hasta un máximo de 7 cuotas mensuales y sucesivas, debiendo cancelarse en el mes de junio de 2020 la primera cuota del $10 \%$ del impuesto liquidado.

Para las solicitudes de autorización de pago a plazos realizadas por sujetos clasificados como grandes contribuyentes, la DGT otorga, mediante la resolución respectiva, hasta un máximo de 4 cuotas mensuales y sucesivas, debiendo cancelarse en el mes de junio de 2020 la primera cuota del $30 \%$ del impuesto liquidado.

El incumplimiento de las resoluciones de pago a plazos, al terminar la vigencia del plazo concedido, da lugar a la pérdida de los beneficios otorgados en el mismo y, en consecuencia, se aplica la gestión de cobro de acuerdo con las leyes tributarias respectivas. 
El artículo 8 de la referida ley, al transcurrir el plazo que establece su artículo 1, sin que se cumpla con el pago dentro de los plazos otorgados, hace caducar los beneficios del decreto y se gestiona el cobro de acuerdo con las normas tributarias aplicables y, en consecuencia, procederá el cobro de las multas y los intereses respectivos.

En el artículo 10 se exonera del pago de multas, intereses y recargos a aquellos sujetos pasivos clasificados como otros, medianos o grandes contribuyentes por parte de la DGII, así como a las personas naturales no inscritas como contribuyentes del IVA, que hubiesen presentado y pagado la declaración del impuesto sobre la renta o solo hubiesen presentado la misma sin efectuar el pago, ni solicitar autorización de pago a plazos, todo ello fuera del plazo legal establecido en la ley que regula el mismo, y antes de la entrada en vigencia del presente decreto, o hubiesen solicitado la autorización de pago a plazos extemporáneamente en dicho lapso.

De igual manera, se exonera del pago de multas, intereses y recargos a aquellos sujetos pasivos clasificados como grandes contribuyentes por parte de la DGII, que hubiesen declarado y pagado la Contribución Especial a los Grandes Contribuyentes para el Plan de la Seguridad Ciudadana o solo hubiesen presentado esta sin efectuar el pago, todo ello fuera del plazo legal establecido en la ley que regula la misma y antes de la entrada en vigencia del decreto.

Así también, se exonera del pago de multas por la presentación de aquellos informes tributarios o cumplimiento de obligaciones formales contenidas en las leyes tributarias respectivas con fecha posterior al 30 de abril de 2020 y hasta la entrada en vigencia del decreto.

Según el artículo 11, también se exonera del anticipo a cuenta del ISR correspondiente a los periodos mensuales de abril, mayo y junio de 2020, a todos los sujetos pasivos clasificados como medianos o como otros contribuyentes por parte de la DGII, pero la obligación formal de presentar la declaración respectiva debe cumplirse dentro del plazo legal establecido en el artículo 152 del CT. De igual manera, subsisten los plazos para cumplir con la declaración y las retenciones mensuales del impuesto sobre la renta.

Además, en el artículo 12 se prorrogó el plazo que establece el inciso segundo del artículo 91 del CT, para presentar el balance general del cierre del ejercicio fiscal 2019, el estado de resultados, las conciliaciones fiscales o justificaciones de los rubros consignados en la declaración y en el balance general, así como el estado de ingresos y gastos, a todos aquellos sujetos pasivos que estén clasificados como medianos o como otros contribuyentes por parte de la DGII, hasta el día 30 de junio de 2020, la cual no causa multas y recargos.

Un dato relevante es que en el artículo 13 declara que son rentas no gravables del impuesto sobre la renta, y, en consecuencia, quedan excluidas del cómputo de la renta obtenida, las derivadas por concepto de bono por compensación para la contención del covid-19, otorgado por el Gobierno de la República mediante el artículo 14 del Decreto Ejecutivo 14 del Ramo de Salud, "Medidas extraordinarias de prevención y contención para declarar el territorio nacional como zona sujeta a control sanitario, a fin de contener la pandemia COVID-19”, de fecha 30 de marzo de 2020. 
En el artículo 1 se prorrogó el plazo para efectuar el nombramiento de auditor fiscal correspondiente al periodo anual de 2020, para todos aquellos contribuyentes que cumplan las condiciones de los literales a) y b) del artículo 131 del CT, hasta el día 31 de julio de 2020, la cual no causa multas.

Además, el artículo 15 prórroga el plazo que establece el párrafo primero del artículo 134 del CT, para presentar el dictamen fiscal conjuntamente con el informe fiscal, los estados financieros, las conciliaciones tributarias e información suplementaria regulada en el Reglamento del CT, correspondiente al periodo anual de 2019, hasta el día 31 de julio de 2020, la cual no causará multas.

El artículo 17 establece una ampliación por un periodo de 2 meses contados a partir del vencimiento del plazo ordinario respectivo, el cumplimiento de obligaciones formales contenidas en las leyes tributarias respectivas no contempladas en el mencionado decreto, que no estén relacionadas con el pago de impuestos o liquidación de remanentes o saldos a favor, relativas a los tributos internos y aduaneros que venzan en los meses de marzo a julio de 2020.

Según el artículo 19, las multas y los intereses que hubieren sido pagados por los sujetos pasivos, la presentación de la declaración de ISR del ejercicio fiscal de 2019 y el pago este fuera del plazo legal regulado en el artículo 48 de la Ley del Impuesto en referencia, hasta la entrada en vigencia de esta ley, podrán ser acreditados contra el impuesto liquidado en la declaración del referido gravamen correspondiente al ejercicio fiscal de 2019. De igual forma podrán acreditarse las multas e intereses que hubieren pagado, en los casos que hubiesen presentado y pagado la declaración de la Contribución Especial a los Grandes Contribuyentes para el Plan de la Seguridad Ciudadana fuera del plazo legal establecido en la ley de la referida Contribución Especial.

\section{F. Devoluciones de impuestos}

Conforme al artículo 215 del CT, la AT, por medio de la DGII, resuelve las solicitudes de devoluciones del ISR consignadas en las declaraciones de dicho tributo $\mathrm{y}$, de ser favorable al contribuyente, autoriza el pago de tales montos, lo cual en el caso de del ejercicio inmediato anterior corresponde a realizar los pagos a la DGT en un término de hasta 120 días después de emitida la resolución, tal como se transcribe a continuación:

La Administración Tributaria deberá ordenar mediante resolución, dentro de los sesenta días hábiles siguientes a la presentación de la solicitud correspondiente y previas las compensaciones que resulten aplicables, la devolución o compensación, según sea el caso, salvo que se den las situaciones que establece el siguiente artículo. Para proceder a la devolución se requiere informe previo de la DGT de que las sumas cuya devolución se trata, han ingresado al Fondo General de la Nación.

Ordenada la devolución, la misma deberá efectuarse dentro de los ciento veinte días siguientes a la notificación correspondiente. 
Según el Ministerio de Hacienda a través de su página www.mh.gob.sv, hasta el 27 de mayo de 2020 se habían pagado \$13,5 millones de dólares de los Estados Unidos de América por concepto de devoluciones del ISR del ejercicio 2019, a un total de 78.882 contribuyentes, quienes presentaron su declaración entre el 1 de enero y el 26 de febrero de 2020; esto indica una sobresaliente continuidad en el proceso de devoluciones durante los meses de marzo, abril y mayo de 2020, periodo que hasta la fecha de redacción de este artículo duraba la emergencia decretada por el Gobierno, entre otros propósitos, para tomar medidas de distanciamiento social y suspensión de la actividad económica y laboral, casi en su totalidad, con la finalidad de contrarrestar la propagación del virus. Como señala elsalvador.com del 16 de abril de 2020: "Según datos del Ministerio de Hacienda, hasta el 14 de abril se habían recibido 316.647 declaraciones, 64.448 menos que en relación con 2018. El número de declaraciones presentadas solo es el 55,26\% de las que se esperan recibir (573.000)".

\section{G. Servicios digitales}

La AT, por medio de la DGII, puso a disposición servicios en línea ${ }^{1}$, donde los contribuyentes pueden solicitar y obtener de forma automática solvencias tributarias, ingresando únicamente su número de identificación tributaria (NIT) y su contraseña personal de acceso, previo registro del contribuyente en la plataforma electrónica, y siempre que se cumpla con las condiciones de pago establecidas, sin perjuicio del artículo 219 inciso segundo del CT; en caso contrario los contribuyentes pueden obtener el estado de su cuenta tributaria.

También, se ha facilitado el registro a los contribuyentes para que utilicen todos los servicios en línea de la $\mathrm{AT}^{2}$ hasta el 30 de junio de 2020, para realizar su declaración y pago del ISR 2019. Para ello, los contribuyentes deben ingresar utilizando su número de documento único de identidad (DUI), el NIT, correo electrónico y los datos de la constancia de retención del ISR.

Por otra parte, las personas jurídicas pueden realizar la inscripción en IVA y el Registro Único de Contribuyentes dirigiéndose a la cuenta de correo electrónico de la Asistencia Tributaria de la DGT donde presentan la solicitud ${ }^{3}$.

Para gozar de los beneficios que otorga la Ley de Facilitación de Obligaciones Tributarias, la AT ha emitido una guía que los contribuyentes pueden consultar en internet ${ }^{4}$.

1 Para acceder a los servicios en línea, los contribuyentes deben registrarse en: https://portaldgii.mh.gob.sv/ssc/ pi/registro/

2 Deben ingresar a http://mh.gob.sv

3 Deben ingresar a asistenciadgii@mh.gob.sv

4 Se puede consultar en el siguiente enlace: https:/www.mh.gob.sv/downloads/pdf/700-DGII-GA-2020-22121. pdf 
También están disponibles los call center, donde los contribuyentes pueden llamar a consultar.

\section{Conclusiones}

El Salvador no es ajeno a la realidad global y, por ende, el Gobierno tomó una serie de medidas para intentar mitigar los efectos de la pandemia en la economía del país y, por ello, las regulaciones dadas en materia tributaria están a la orden del día. De todas formas, más allá de las regulaciones concretas, la receta salvadoreña no dista mucho de la aplicada en casi toda América Latina, como se relaciona a continuación:

\section{Prórrogas de fechas de presentación y pago}

Aplicables a grandes contribuyentes

- Prórroga al 30 de junio de 2020, de la Declaración del ISR del ejercicio 2019 que vencía el 30 de abril de 2020.

- Prórroga al 30 de junio de 2020, de la presentación y pago de la Contribución Especial para e1 Plan de Seguridad Ciudadana del año 2019.

- Prórroga de 2 meses a las obligaciones formales de los meses de marzo, abril, mayo, junio y julio de 2020, no relacionadas con el pago de tributos internos y aduanas.

- Prórroga al 31 de julio de 2020, para nombrar auditor fiscal.

- Prorroga al 31 de julio de 2020, para presentar el Dictamen e Informe Fiscal.

Aplicables a los medianos y otros contribuyentes

- Prórroga al 30 de junio de 2020, para declarar el ISR del año 2019 que vencía el 30 de abril de 2020.

- Prórroga al 31 de julio de 2020, para nombrar auditor fiscal, para presentar el Dictamen e Informe Fiscal.

- Prórroga de 2 meses a partir de la vigencia del decreto, para presentar informes tributarios u obligaciones formales, que vencían el 30 de junio de 2020.

- Prórroga de 2 meses a las obligaciones formales que vencían de marzo a julio de 2020, no relacionadas con el pago de tributos internos y aduanas.

- Extensión de plazo de presentación al 30 de junio de 2020, del Balance General, Estado de Resultados, conciliaciones fiscales, justificaciones de rubros declarados y del estado de ingresos y gastos del ejercicio 2019.

Exenciones y exoneraciones

- Exención de intereses, recargos y multas. 
- Exoneración del valor de pago a cuenta del ISR, en declaraciones de los meses de abril, mayo y junio de 2020 .

- Exención de derechos arancelarios, IVA y cualquier otro impuesto fiscal o municipal a los bienes internados al amparo de la Ley de Zonas Francas Industriales y de Comercialización donados al Gobierno, alcaldías, instituciones públicas y privadas, sin fines de lucro, de carácter humanitario, educativas u otros servicios a la comunidad en beneficio de las personas afectadas por el covid-19.

Aplicables a los medianos y otros contribuyentes

- Facilidades para pagar y cumplir otras obligaciones formales.

- Facilidad de pago del ISR del ejercicio 2019, en 4 cuotas mensuales, a partir de junio, con una prima del $30 \%$.

- Facilidad para pagar el ISR en 7 cuotas mensuales a partir de junio de 2020, con una primera cuota del $10 \%$, incluso para quienes declararon el ISR 2019 antes de la vigencia del decreto, hayan solicitado en su momento pagar a plazo o no.

- Posibilidad de modificar al 30 de junio de 2020, la declaración del IsR del año 2019 presentada antes del decreto, tanto cuando liquiden valor a pago, excedentes o remanentes.

\section{Referencias}

Ministerio de Hacienda de El Salvador (s.f.). Home. https://www.mh.gob.sv

Ministerio de Hacienda de El Salvador (2020). Guía de orientación para aplicar la ley transitoria para facilitar el cumplimiento voluntario de obligaciones tributarias en virtud de la emergencia nacional ocasionada por la pandemia por covid-19. https://www.mh.gob.sv/downloads/pdf/700-DGII-GA-2020-22121.pdf

\section{Normativa}

Decreto Legislativo 598. Ley especial y transitoria sobre la modalidad de pago del ISR aplicable a pequeños contribuyentes, turismo, energía eléctrica, servicios de televisión, internet y telefonía y sobre la contribución especial para la promoción del turismo. Diario Oficial 58, tomo 426 de 20 de marzo de 2020.

Decreto Legislativo 601. Ley transitoria para diferir el pago de facturas de servicios de agua, energía eléctrica y telecomunicaciones (teléfono, cable e internet). Diario Oficial 58, tomo 426, de 20 de marzo de 2020, reformado según Decreto Legislativo 618, de 1 de marzo de 2020. Diario Oficial 70, tomo 3427 de 3 de abril de 2020.

Decreto Legislativo 603. Disposiciones transitorias por medio de las cuales se simplifica el procedimiento de las donaciones de bienes por parte de las empresas reguladas 
en la ley de zonas francas industriales y de comercialización. https://www.mh.gob. sv/pmh/es/Temas/Medidas-Economicas-Fiscales-emergencia-COVID-19.html

Decreto Legislativo 604. Modificación del arancel centroamericano de importación. Diario Oficial 58, tomo 426 de 20 de marzo de 2020.

Decreto Legislativo 643. Ley Transitoria para facilitar el cumplimiento voluntario de obligaciones tributarias en virtud de la emergencia nacional ocasionada por la pandemia por covid-19. Diario Oficial 98, tomo 427 de 15 de mayo de 2020.

Fecha de recepción: 24 de junio de 2020

Fecha de aprobación par 1: 08 de septiembre de 2020

Fecha de aprobación par 2: 07 de septiembre de 2020 